\title{
Rising to the GINA Asthma Challenge: thinking beyond just asthma
}

\section{To the Editors:}

We welcome the Global Initiative for Asthma (GINA) Asthma Challenge outlined in the recent editorial by FitzGerALD et al. [1], which discussed the goal of achieving a 50\% reduction in hospital admissions due to asthma over the next 5 yrs. However, successfully addressing this challenge requires an understanding of the complex nature of asthma. Our evolving understanding of asthma shows it to be a heterogeneous state with numerous phenotypes influenced by many aggravating factors. All these factors will need addressing to meet the GINA Asthma Challenge effectively.

We recently assessed asthma admission at Southampton General Hospital (Southampton, UK), focusing on the annual burden of repeated asthma admissions and their relation to aggravating comorbidities. Our findings may prove informative to meeting the GINA Asthma Challenge.

We systematically searched the hospital database for patients who had been acutely admitted on two or more occasions in 2010 for asthma at Southampton General Hospital. Data were collected retrospectively and covered patient demographics, admission details, asthma severity, and physical and psychiatric comorbidity. A diagnosis of psychiatric disease was made if the patient was on antidepressant medication, had a diagnosis documented in their general practitioner's records or had evidence of care under a psychiatrist. A clinical diagnosis of vocal cord dysfunction was made based on clinical history and examination findings. A clinical diagnosis of dysfunctional breathing was based on a combination of clinical history, examination findings and Nijmegen score. Where available, data were collected to characterise disease severity including baseline spirometry, eosinophil counts and immunoglobulin E. Coding data for each admission were analysed to determine admission costs. Data were analysed using SPSS (version 19.0; IBM, Armonk, NY, USA).

Our findings showed there were 396 admissions for acute asthma in 2010, involving 305 patients. Of these, $36(11.8 \%)$ patients were admitted on two or more occasions, accounting for $32.1 \%$ of admissions. Several of these patients were known to our Difficult Airways Clinic (Southampton General Hospital) and under specialist surveillance for their asthma. Repeated-admission patients consumed 895 bed-days and were predominantly female $(72.2 \% ; p=0.012)$. They commonly had aggravating comorbidities, the most predominant being diagnosed psychiatric disease $(69.4 \%$; $=0.03)$. Those patients with psychiatric comorbidity showed significantly higher body mass index (BMI) $(p=0.012)$, and greater prevalence of obesity $(\mathrm{p}=0.05)$ and dysfunctional breathing $(\mathrm{p}=0.012)$ than patients without psychiatric comorbidity. They also showed trends for higher prevalence of other aggravating comorbidity such as gastro-oesophageal reflux disease $(p=0.07)$ and for greater median bed-days/length of stay. The annual cost for repeated asthma admission was
$£ 226,536$ of which patients with psychiatric comorbidity consumed $£ 164,660$ (72.7\% of costs).

These findings support a growing awareness of the impact of psychological comorbidity on asthma. The relationship between asthma and psychological comorbidity is not clearly understood. Psychological comorbidity may lead to asthma or may be the result of living with a chronic disease. LIETZEN et al. [2] found that greater exposure to stressful life events predicted the onset of asthma in a population-based cohort study whereas BosLEY et al. [3] studied compliance and psychiatric disease and found higher rates of depression in patients who were not compliant with their inhaled asthma therapies. Research is needed into the efficacy of addressing psychological comorbidity in asthma populations.

The patients with repeated admissions in our study were predominantly female and had a higher prevalence of obesity. This group may be synonymous with a specific group identified in recent cluster analysis studies. MoORE et al. [4] identified a group of older female patients (Cluster 3) with raised BMI, late-onset asthma, high healthcare utilisation and daily symptoms out of proportion to the degree of airflow obstruction demonstrated. HALDAR et al. [5] also describe a phenotype (Cluster 2) that was predominantly female, obese and nonatopic. Our data suggest that this relatively small asthma phenotype may be responsible for a high number of asthma admissions. Addressing the needs of this group may help reduce their asthma admission rates.

In conclusion, we suggest that to meet the GINA Asthma Challenge, respiratory specialists need to understand and recognise factors that influence asthma hospital admission. Proactively addressing factors such as psychological comorbidity along with inter-related problems such as dysfunctional breathing and obesity may offer useful strategies to achieve that in the frequently admitted population. Further research in this area is indicated.

\section{Zoe Pond*, Hannah Burke", Claire Duffus" and Ramesh J. Kurukulaaratchy ${ }^{\#}$ \\ *Dept of Respiratory Medicine, Queen Alexandra Hospital, Portsmouth, and "Dept of Respiratory Medicine, Southampton General Hospital, Southampton, UK.}

Correspondence: R.J. Kurukulaaratchy, Dept of Respiratory Medicine, Southampton General Hospital, Tremona Road, Shirley, Southampton, SO16 6YD, UK. E-mail: Ramesh.Kuruk ulaaratchy@uhs.nhs.uk

\section{Statement of Interest: None declared.}

\section{REFERENCES}

1 FitzGerald JM, Bateman E, Hurd S, et al. The GINA Asthma Challenge: reducing asthma hospitalisations. Eur Respir J 2011; 38: 997-998. 
2 Lietzen R, Virtanen P, Kivimaki M, et al. Stressful life events and the onset of asthma. Eur Respir J 2011; 37: 1360-1365.

3 Bosley C, Fosbury JA, Cochrane GM. The psychological factors associated with poor compliance with treatment with asthma. Eur Respir J 1995; 8: 899-904.

4 Moore CM, Meyers DA, Wenzel SE, et al. Identification of asthma phenotypes using cluster analysis in the severe asthma research program. Am J Respir Crit Care Med 2010; 181: 315-323.

5 Haldar P, Pavord ID, Shaw DE, et al. Cluster analysis and clinical asthma phenotypes. Am J Respir Crit Care Med 2008; 178: 218-224.

DOI: $10.1183 / 09031936.00036712$

\section{From the authors:}

We would like to thank Z. Pond and co-workers for their interest in our recent editorial with regard to the Global Initiative for Asthma (GINA) Asthma Challenge [1]. We are also delighted by their enthusiasm, in terms of embracing this concept, and framing the issue in the context of their local population. We recognise that the GINA recommendations provide a framework for the management of asthma in the general population of patients [2], but it is also recognised, within the body of the document, that management needs to be individualised. As Z. Pond and co-workers have outlined patient management must go beyond the appropriate prescription of medications, but also take account of the sociocultural factors $[3,4]$ as well as the importance of psychological issues as outlined in their audit [5]. We also feel that the assessment of the phenotype of asthma patients should take account of these factors as they are likely to contribute to an increased risk of hospitalisation. We strongly recommend that others embrace this approach of adapting locally our global challenge to reduce asthma hospitalisations. We suggest that by using the GINA asthma strategy as a framework for achieving asthma control that we can move closer to achieving our ultimate aim of reducing morbidity and mortality associated with this global public health challenge. It should be noted that our challenge of a $50 \%$ reduction in hospitalisations is targeted at a general population level and we appreciate that this may not be feasible in a more specialised setting, such as Z. Pond and co-workers working at a tertiary or quaternary level.
J. Mark FitzGerald*, Eric D. Bateman", Suzanne Hurd", Louis-Philippe Boulet ${ }^{+}$, Tari Haahtela ${ }^{\S}$, Alvaro A. Cruz ${ }^{\dagger}$ and Mark L. Levy**

*Respiratory Division, Dept of Medicine, Vancouver Hospital and Health Science Centre, Vancouver, BC, ${ }^{+}$Institut Universitaire de Cardiologie et de Pneumologie de Québec, Université Laval, Quebec, QC, Canada. "Lung Institute, University of Cape Town, Cape Town, South Africa. 'Global Initiative for Asthma, Vancouver, WA, USA. ${ }^{\S}$ Dept of Allergy, Helsinki University, Helsinki, Finland. ${ }^{f}$ ProAR - Nucleo de Excelência em Asma of Federal, University of Bahia, Salvador, Brazil. **Primary Care Research and Development, Division of Community Health Sciences, GP Section, University of Edinburgh, Edinburgh, UK.

Correspondence: M.J. Fitzgerald, Respiratory Division, Dept of Medicine, Vancouver Hospital and Health Science Centre, 2775 Heather Street, Vancouver, BC, V5Z 3J5, Canada. E-mail: markf@interchange.ubc.ca

Statement of Interest: Statement of interests for J.M. FitzGerald, L-P. Boulet, T. Haahtela and M.L. Levy can be found at www.erj. ersjournals.com/site/misc/statements.xhtml

\section{REFERENCES}

1 FitzGerald JM, Bateman E, Hurd S, et al. The GINA Asthma Challenge: reducing asthma hospitalisations. Eur Respir J 2011; 38: 997-998.

2 Bateman ED, Hurd SS, Barnes PJ, et al. Global strategy for asthma management and prevention: GINA executive summary. Eur Respir J 2008; 31: 143-178.

3 Poureslami I, Rootman I, Doyle-Waters MM, et al. Health literacy, language, and ethnicity-related factors in newcomer asthma patients to Canada: a qualitative study. J Immigr Minor Health 2011; 13: 315-322.

4 Poureslami I, Nimmon L, Doyle-Water MMR, et al. Using community-based participatory research (CBPR) with ethno-cultural groups as a tool to develop culturally and linguistically appropriate asthma educational material. Divers Health Care 2011; 8: 203-215.

5 Alvarez GG, FitzGerald JM. A systematic review of the psychological risk factors associated with near fatal asthma or fatal asthma. Respiration 2007; 2: 228-236. 